\title{
Second-Hand Smoke in a University Campus: Attitudes and Perceptions of Faculty, Staff and Students
}

\section{Abstract}

Purpose: To examine the attitudes and perceptions of faculty, staff and students concerning tobacco policies at a university campus in a tobacco producing state.

Methods: A questionnaire was administered to faculty, staff and students to assess knowledge, attitudes and beliefs related to smoking and exposure to second-hand smoke on campus. A 3-wave e-mailing was used to send the questionnaire.

Results: A total of 2,914 individuals responded to the questionnaire. Majority (60\%) of the participants believed a smoke free policy would be a positive move and could possibly improve the quality of life for the campus community, while not negatively affecting student enrollment status.

Conclusion: Implementing a smoke free policy in university campuses in North America could be acceptable to faculty, staff and students and is unlikely to reduce students enrolment. Our findings have the potential to support efforts to implement smoke free policies on university campuses in North America.

Keywords: Second-hand smoke; Tobacco policies; Perceptions; Faculty; Staff; Students; University campus.

\author{
Sandeep Mishra ${ }^{1}$ \\ Herpreet Kaur Thind ${ }^{2}$ \\ Srinivasa B Gokarakonda ${ }^{3}$ \\ Grace Lartey $^{3}$ \\ Cecilia Watkins $^{3 *}$ \\ Monia Chahal $^{3}$ \\ Department of ${ }^{1}$ Epidemiology, and ${ }^{2}$ Health \\ Behavior, University of Alabama at \\ Birmingham, USA. \\ ${ }^{3}$ Western Kentucky University, Department of \\ Public Health, USA. \\ *For correspondence: \\ Tel: 270-745-4796 \\ Email: cecilia.watkins@wku.edu
}

This article is available in Embase, Index Corpenicus, Scopus, PubsHub, Chemical Abstracts, Socolar, EBSCO, African Journal Online, African Index Medicus, Open-J-Gate, Directory of Open Access Journals (DOAJ) databases

\section{Introduction}

According to the United States (US) Surgeon General's report, "Smoking is the single greatest avoidable cause of disease and death" [1]. Even with this important information, $20.8 \%$ of the U.S. adult population continues to smoke cigarettes. Kentucky, one of the top tobacco- producing states in the nation, has the highest smoking statistics of any state in the US with a rate of $28.6 \%$ for adults and $31 \%$ for young adults [2].

Second-hand smoke (tobacco smoke in the environment that can be inhaled by non-smokers) [3] exposure in the workplace presents a similar public health threat. Barnes, Hammond and Int J Health Res, March 2011; 4(1): 21 
Glantz reanalyzed data from the 16 Cities Study (conducted in 1996 by the tobacco industry) and found that smoke-free workplaces noticeably reduced total second-hand smoke exposure [4]. An investigation by Fichtenberg and Glantz studying the effects of smoke-free workplaces on cigarette consumption found that if all workplaces became smoke-free, consumption of cigarettes per day per capita in the United States would drop by $4.5 \%$ [5]. This study also concluded that smoke-free workplaces protect non-smokers from the dangers of passive smoke and increase smokers' ability to quit or reduce consumption.

In the US the Substance Abuse and Mental Health Service Administration (SAMHSA) reported that cigarette smoking among fulltime college students aged 19 had increased from $24.4 \%$ in 2005 to $28.8 \%$ in 2006 ; but decreased for 20 year olds ( 32.3 to $27.2 \%$ ) and 21 year olds (36.3 to $30.2 \%$ ) [6]. This trend presents the possibility that as students settle into college life, they may reexamine their choices of lifestyle habits. College campuses around the nation are often dynamic environments of diversity and change. Along with diversity comes a tolerant atmosphere, which can present opportunities to have health-enhancing policies implemented, which if enforced effectively, can positively influence the health of faculty, staff and students. One of the more obvious opportunities is a policy enforcing a smoke-free environment.

College years are frequently a young adult's first experience with total independence. Along with this independence come lifestyle choices. Social smoking, defined as individuals who smoke mainly with others and not alone, is common among college students and may predispose them to a lifetime of nicotine addiction [7]. Durham conducted a study which revealed that approximately one third of young adults (ages 1824) attend a college or university out of which approximately $12 \%$ smoked daily, while $24 \%$ had smoked a cigarette within a one month period. Most of the students in this study thought of themselves as "social smokers" and that smoking was a "harmless pleasure" [8]. Students think they can quit smoking once they graduate from college. By graduation, the students are addicted to the nicotine, and have become lifetime smokers.

The probability of smoking among college students is strongly guided by risky lifestyle behaviors such as having multiple sex partners, using marijuana and heavy drinking habits. Other lifestyle factors that may encourage smoking include memberships in fraternities or sororities and residing in a coed dorm. Students who are not satisfied by their academic performance are also more often smokers [9]. An investigation by Patterson, Lerman, Kaufmann, Neuner and Audrain-McGovern revealed that $31.9 \%$ of students smoked if they were depressed, while $49.3 \%$ smoked to fight stress. Students believed smoking made them less anxious. Among smokers in college, $55 \%$ of students who smoked everyday were aware that smoking was dangerous for their health. As per the study, undergraduate female students were more likely to smoke if they were dieting and overweight [10]. Female college students who smoke cite stress as their primary reason for smoking [11].

Research has shown that living in university housing which allows smoking influences college students smoking habits [10]. A similar study by Wechsler, Lee and Rigotti examined students' probability of smoking in college. The study concluded that smoking prevalence was $21 \%$ lower in students in smoke-free housing than in residents of unrestricted housing [12]. The health belief model takes into account the perception of susceptibility and severity of consequences of health behaviors. In a study examining predictors of health behaviors in college students, Von Ah, Ebert, Ngamvitroj, Park and Kang identified higher self-efficacy as an important predictor of all health behaviors (alcohol, physical activity/nutrition, general safety and sunprotection) examined, except smoking. One possible speculation for this conclusion was that students were convinced that they would be able to quit smoking in the future. The students' perceptions of their susceptibility to nicotine addiction and the long term consequences of that addiction could be influenced by a youthful attitude of "it can't happen to me"[13].

Int J Health Res, March 2011; 4(1): 22 
A national survey designed to measure student support of tobacco control policies on college campuses concluded that student, non-smokers and smokers, were strongly in favor of campus control policies [14]. Another study conducted at a mid-western university supports these findings. This study found that regardless of gender or tobacco use, the majority of college students supported a smoking ordinance [15]. A survey conducted by Glantz \& Jamieson assessed the impact of attitudes toward second-hand smoke among young people and concluded that educating young people about the dangers of second-hand smoke empowered nonsmokers to speak out against exposure to second-hand smoke [16]. A review of interventions to reduce tobacco use in colleges and universities found that smokefree policies and other interventions resulted in a reduction of smoking among college students and an increasing acceptability of smoking policies among smokers and non-smokers [17].

The purpose of this study was to examine the attitudes and perceptions of faculty, staff and students concerning tobacco policies at a university campus in a tobacco state. The results of this study could help to determine if cultural background along with other factors would influence the attempt to strengthen smoking policies already in place at this university.

\section{Methods}

\section{Participants}

This consisted of all faculty, staff and students registered on the university's e-mail network which were made up of 2,385 faculty and staff, 15,366 undergraduate students, and 2,673 graduate students in the spring of 2009 .

\section{Research Instrument}

A 26 item questionnaire assessing the knowledge, attitudes and beliefs related to smoking and second hand smoke on this campus was developed. The questions were derived from the literature survey and a focus group discussion involving 14 participants from a college environment. Researchers assessed the face value of the instruments. The instruments looked at the following areas of second-hand exposure: perceived health consequences, perceived health benefits of a smoke-free environment, policies and procedures. An example of the questions used to measure the perceptions of smoking and secondhand smoke by faculty, staff and students included (1) I believe smoking is harmful to my health, (2) I believe exposure to secondhand smoke is harmful to my health, (3) I am concerned about the effect of secondhand smoke on the campus community, (4) I believe the university administration is responsible for protecting the campus community from exposure to secondhand smoke, and (5) I believe the smoking policy is effectively enforced on campus

The instrument and survey procedure were approved by the university's Institutional Review Board prior to administration.

\section{Procedures}

A 3-wave e-mailing was used to send questionnaires to all registered e-mail users in the University campus. The first e-mail consisted of a cover letter explaining the confidentiality, purpose of the study and the incentive, which consisted of all participants being eligible to win 1 of 3 MP3 players. Two weeks later, a follow-up e-mail containing a cover letter and the questionnaire was sent out. Two weeks after the second e-mail, a third and final e-mail reminder with the questionnaire was sent out. Three participants were randomly selected (one faculty, one staff and one student) as winning participants to each receive an MP3 player.

\section{Data Analysis}

Data collected were entered into SPSS 16.0, double checked and analyzed. Descriptive statistics (frequencies, means and standard deviations) were used to describe the responses. Chi square test were used to describe associated between variables. Analysis of variance (ANOVA) was also used to determine the relationships between the independent and dependent variables. 


\section{Results}

\section{Characteristics of respondents and prevalence}

Table 1 shows a total of 2,914 individuals responded to the survey. The majority of respondents were female $(65 \%)$; undergraduates $(71 \%)$, and between 16 and 25 years old $(65 \%)$. Eighty-six percent of respondents were white and $74 \%$ of respondents have had some college education.

Table 1: Demographic and background characteristics of respondents

\begin{tabular}{|c|c|}
\hline Item & Number $(\%)$ \\
\hline \multicolumn{2}{|l|}{ Gender } \\
\hline Female & $1897(65)$ \\
\hline Male & $986(34)$ \\
\hline Missing & $31(1)$ \\
\hline \multicolumn{2}{|l|}{ Status } \\
\hline Faculty & $193(7)$ \\
\hline Staff & $291(10)$ \\
\hline Graduate & $317(11)$ \\
\hline Undergraduate & $2088(71)$ \\
\hline Missing & $25(1)$ \\
\hline \multicolumn{2}{|l|}{ Age (yrs) } \\
\hline $16-25$ & $1899(65)$ \\
\hline $26-35$ & $405(14)$ \\
\hline $36-45$ & $275(9)$ \\
\hline $46+$ & $295(11)$ \\
\hline Missing & $40(1)$ \\
\hline \multicolumn{2}{|l|}{ Race } \\
\hline White & $2418(86)$ \\
\hline Black & $123(5)$ \\
\hline Asian/Pacific Islander & $110(4)$ \\
\hline Hispanic & $34(1)$ \\
\hline Other & $90(3)$ \\
\hline Missing & $39(1)$ \\
\hline \multicolumn{2}{|l|}{ Level of Education } \\
\hline Doctorate & $132(5)$ \\
\hline Master's & $379(13)$ \\
\hline Some college & $2170(74)$ \\
\hline High school & $186(6)$ \\
\hline Less than high school & $18(1)$ \\
\hline Missing & $29(1)$ \\
\hline
\end{tabular}

The respondents' perception regarding campus smoking policy is presented in Table 2. Fiftyeight percent of respondents did not believe the current smoking policy was being enforced. Forty-four percent of them disagreed to the idea that a complete smoke free policy would increase enrollment. However, $60 \%$ of them agreed that a complete smoke free policy would improve on the quality of life of students. Sixty-one percent of respondents believed they had the right to breathe clean air.

The ANOVA test revealed that differences existed between respondents' status and their belief that the campus should be smoke free $(\mathrm{F}=$ 18.69 , df $=3, p<0.01)$. Compared to graduate students, faculty and staff, undergraduate students believed the entire campus should be smoke free $(\mathrm{M}=0.58, \mathrm{SD}=0.49)$. Chi-square analyses determined an association between smoking status and a smoke free campus.

Seventy-three percent of nonsmokers believed the entire campus should be smoke free $\left(\chi^{2}=685\right.$, df $=1, \mathrm{p}<=0.01)$. Besides, the majority of respondents believed the campus should be smoke free $\left(\chi^{2}=55\right.$, df $\left.=3, \mathrm{p}<0.01\right)$ : faculty $(75 \%)$; staff (73\%); graduate students $(71 \%)$; and undergraduate students $(56 \%)$. On the other hand, only $34 \%$ of smokers who have never thought of quitting and $11 \%$ of smokers who have ever thought of quitting believed the campus should be smoke free $\left(\chi^{2}=30, \mathrm{df}=1, \mathrm{p}<0.01\right)$.

Chi-square analysis was conducted on respondents' status and their awareness of current smoking policy on the university campus. A statistically significant association was found $\left(\chi^{2}\right.$ $=45.77, \mathrm{df}=3, \mathrm{p}<0.01)$. The majority of respondents were aware of the current smoking policy on campus (faculty: $76 \%$; staff: $86 \%$; graduate students: $62 \%$; undergraduate students: $73 \%)$.

Table 3 included the respondents' perceptions regarding secondhand smoke. An examination of respondents' perceptions regarding secondhand smoke found the majority of them believing that secondhand smoke was harmful. Specifically, $89 \%$ of respondents agree or strongly agreed that

Int J Health Res, March 2011; 4(1): 24 
Table 2: Respondents' perceptions regarding smoking policy on campus

\begin{tabular}{|c|c|c|c|}
\hline Variable & SA/A $(\%)$ & NS $(\%)$ & $\mathrm{SD} / \mathrm{D}(\%)$ \\
\hline Smoking policy is effectively enforced & $584(20)$ & $1078(37)$ & $1233(58)$ \\
\hline Smoking is my individual right & $395(14)$ & $41(1)$ & $77(15)$ \\
\hline Complete smoke free policy will improve quality of life of studen & $1745(60)$ & $363(13)$ & $764(27)$ \\
\hline Complete smoke free policy will increase enrollment & $492(17)$ & $1113(38)$ & $1266(44)$ \\
\hline A smoke free campus will help me quit & $72(3)$ & $65(2)$ & $391(8)$ \\
\hline I have the right to breathe clean air & $2596(61)$ & $167(6)$ & $127(4)$ \\
\hline
\end{tabular}

$S A=$ strongly agree; $A=$ agree $; S D=$ strongly disagree; $D=$ disagree $; N S=$ not sure; *Missing $=19-2401$

Table 3: Respondents' perceptions regarding secondhand smoke

\begin{tabular}{|c|c|c|c|}
\hline Variable & SA/A $(\%)$ & NS $(\%)$ & $\mathrm{SD} / \mathrm{D}(\%)$ \\
\hline \multicolumn{4}{|l|}{ I believe secondhand smoke is: } \\
\hline Harmful to my health & $2595(89)$ & $100(4)$ & $197(7)$ \\
\hline Increases the chances of developing lung cancer & $2505(86)$ & $203(7)$ & $191(7)$ \\
\hline \multicolumn{4}{|l|}{ I am concerned about the effect of secondhand smoke: } \\
\hline On campus community & $1987(69)$ & $296(10)$ & $604(21)$ \\
\hline \multicolumn{4}{|l|}{ I believe the administration is responsible for: } \\
\hline Protecting the community from secondhand smoke & $1744(60)$ & $410(14)$ & $740(26)$ \\
\hline It is difficult for me to avoid secondhand smoke on campus & $1321(45)$ & $310(110$ & $1262(44)$ \\
\hline
\end{tabular}

$S A=$ strongly agree; $A=$ agree $; S D=$ strongly disagree; $D=$ disagree; $N S=$ not sure $; *$ Missing =18-27

secondhand smoke was harmful to their health, and $86 \%$ of them believed it increased their chances of developing lung cancer. Whereas $44 \%$ believed avoiding secondhand smoke on campus was not difficult, $60 \%$ of respondents agreed or strongly agreed that the university administration was responsible for protecting the campus community from secondhand smoke.

\section{Respondents' Perceptions on the Health Risks of Smoking on Other People}

The perceptions of individuals who classified themselves as smokers regarding the health risks of smoking on other people were assessed. Fortyfour percent of smokers were indifferent about the health risks of smoking on other people, while $27 \%$ of smokers did not believe smoking poses a health risk to other people. On the other hand, $29 \%$ of smokers agreed or strongly agreed that smoking poses a health risk to other people.

Respondents were asked if their exposure to second hand smoke was harmful to their health using ANOVA test and a significant difference was found $(\mathrm{F}=3.70, \mathrm{df}=3, \mathrm{p}<0.05)$. Compared to undergraduate students $(\mathrm{M}=4.09, \mathrm{SD}=0.91)$, faculty believed second hand smoke was more harmful to their health $(\mathrm{M}=4.28, \mathrm{SD}=0.89)$. Examination of respondents' perceptions on whether second hand smoke was harmful to their health by their smoking status showed a statistically significant difference $(\mathrm{t}=27.70$, $\mathrm{df}=$ 2897, $\mathrm{p}<0.01)$. Compared to smokers $(\mathrm{M}=3.16$, $\mathrm{SD}=0.84)$ non-smokers believed second hand smoke was more harmful to their health $(\mathrm{M}=$ 4.29, $\mathrm{SD}=0.81$ ).

\section{Discussion}

This study was an initial effort to examine the perceptions and attitudes of students, faculty and staff concerning tobacco-free policies on campus. As the results revealed, low responses from faculty and staff have skewed the results toward a student majority. Majority of the respondents believed a smoke free policy on the university's campus which is a positive move that could improve the quality of life for students, faculty and staff. Second-hand smoke is also believed to be harmful to their health and hence the need for the campus to be smoke-free. This is consistent with the findings in the Rigotti study that concluded strong support for tobacco policies by Int J Health Res, March 2011; 4(1): 25 
students [14]. While a majority of respondents were aware of the current campus smoking policy, the policy is perceived as not being enforced. The acknowledgement by the respondents of their rights to breathe clean air and the responsibility of the campus administration to protect the campus community from exposure to second-hand smoke in this study is note worthy. Our finding reinforces earlier report that second hand smoke exposure is an important health issue on university campuses [15]. The implication of this is that administration of university campuses in North America need to be conscious of the fact that they could be blamed for adverse health consequences of second-hand smoke exposure of their staff, faulty and students if they fail to develop and enforce smoke free policies on their campuses. Enforcement of the policies can serve as an effective intervention for students at a time when unhealthy behaviors may be developed [9]. As the Murphy-Hoefer, Griffith, Pederson, Crossett, Iyer, and Hiller review revealed, smoke free policies in addition to other interventions such as smoking restrictions and anti-tobacco messages can reduce smoking rates among college students and boost support for smoking policies [17].

\section{Limitations of the study}

First, the results are based on an online survey which may have led to response bias - a problem with self-reported instruments. A second important limitation of this study is that most faculty and students have access to the internet and email regularly; however, the staff perform a variety of duties, which often does not require access to a computer. A higher response rate from faculty and staff would have provided a more generalized understanding of their perceptions about smoking and second hand smoke. Also, this survey was conducted in a university located in a tobacco growing state with a low response rate; therefore the results cannot be generalized to all universities. More studies need to be conducted involving multiple universities to get a better evidence of the perceptions related to smoking and second hand smoke exposure on a university campus.

\section{Conclusion}

Students, faculty and staff are aware of the problem of second hand smoke and many believe that smoke free policies can improve the quality of life on campuses. Implementing a smoke free policy in university campuses in North America could be acceptable to faculty, staff and students and is unlikely to reduce students enrolment. Our findings have the potential to support efforts to implement smoke free policies on university campuses in north America

\section{Contributions of Authors}

We declare that this work was done by authors named in this article and all liabilities pertaining to claims relating to the content of this article will be borne by the authors. SM, HT and SG carried out questionnaire design, implementation, and collection of data. CW and GL carried out manuscript preparation and coordination of the study as well as data analysis. MC contributed to the literature review and revision of the article. All authors read and approved the final manuscript.

\section{Competing Interest}

The authors declare that they have no competing interests.

\section{References}

1. U.S. Department of Health and Human Services. The Health Consequences of Involuntary Exposure to Tobacco Smoke: A Report of the Surgeon General. U.S. Department of Health and Human Services, Centers for Disease Control and Prevention, National Center for Chronic Disease Prevention and Health Promotion, Office on Smoking and Health, 2006.

2. Centers for Disease Control and Prevention. Cigarette Smoking Among Adults --- United States, MMWR 2006, 56(44), 1157-1161. [Cited 2008 Sept 16]. Available from: http://cdc.gov/mmwr/preview/ mmwrhtml/mm5644a2.htm.

3. McKenzie JF, Pinger RR, \& Kotecki JE. An Introduction to Community Health, $6^{\text {th }}$ ed. Jones \& Bartlett. 2008.

4. Barnes LR, Hammond SK, \& Glantz AS. The Tobacco Industry's Role in the 16 Cities Study of

Int J Health Res, March 2011; 4(1): 26 
Secondhand Tobacco Smoke: Do the Data Support the Stated Conclusions. Environl Health Perspect 2006; 114(12): 1890-1897.

5. Fichtenberg MC, Glantz, AS. Effect of smoke-free workplaces on smoking behavior: systemic review. BMJ 2002; 325; 188: 1-7.

6. Substance Abuse and Mental Health Services Administration. Results from the 2006 National Survey on Drug Use and Health: NationalFindings (Office of Applied Studies, NSDUH Series H-32, DHHS Publication No. SMA 07-4293). Rockfield, MD. 2007; 4: 9-13, 46.

7. Moran S, Wechsler H, Rigotti AN. Social Smoking Among US College Students. Pediatrics 2004; 114(4): 1028-1034.

8. Durham A. Smoking Prevalence Among College Students. ISDH: Epi Newsletter, June, 2008, 3. [Cited 2008 Sept 16] Available from: http://in.gov/isdh/23951.htm.

9. Emmons M K, Wechsler H, Dowdall G \& Abraham M. Predictors of Smoking among US College Students. Amer J Public Health 1998; 88: 104-107.

10. Patterson F, Lerman C, Kaufmann GV, Neuner, AG, \& Audrain-McGovern J. Cigarette Smoking Practices Among American College Students: Review and
Future Directions. J Amer Coll Health 2004; 52(5): 203-210.

11. Gaffney FK, Wichaikhum OA., Dawson ME. Smoking among female college students: a time for change. JOGNN 2002; 31: 502-507.

12. Wechsler H, Lee EJ, Rigotti AN. Increased levels of cigarette use among college students. JAMA 2001; 280(1): 202-207.

13. Von Ah D, Ebert S, Ngamvitroj A, Park N, Kang DH. Predictors of health behaviours in college students. $J$ Adv Nurs 2004; 48(5): 463-474.

14. Rigotti N A, Regan S, Moran SE, Wechsler H. Students' opinion of tobacco control policies recommended for US colleges: a national survey. Tobacco Control 2003; 12: 251-256.

15. Smith LM, Applegate T, Seo DC. A preliminary awareness study of tobacco issues among college students. Amer J Health Stud 2006; 21(4): 238244.

16. Glantz AS, Jamieson P. Attitudes toward secondhand smoke, smoking and quitting among young people. Pediatrics 2000; 106: 1-3.

17. Murphy-Hoefer R, Griffith R, Pederson LL, Crossett L, Iyer RS, Hiller DM. A review of interventions to reduce tobacco use in colleges and universities. $\mathrm{Am}$ J Prev Med 2005; 28(2): 188-200.

Int J Health Res, March 2011; 4(1): 27 
Int J Health Res, March 2011; 4(1): 28 